\title{
Should we screen patients for carotid artery disease before lung cancer resection?
}

\author{
Anne Charloux ${ }^{1,2}$, Cézar Matau $^{3}$, Jérémie Jégu $^{4,5}$, Olivier Rouyer ${ }^{1}$, Pierre-Emmanuel Falcoz ${ }^{6}$, \\ Elisabeth Quoix ${ }^{2}$
}

${ }^{1}$ Department of Physiology and Lung Function Testing, University Hospital of Strasbourg, Strasbourg, France; ${ }^{2}$ EA 3072, FMTS, Strasbourg University, Strasbourg, France; ${ }^{3}$ Department of Pulmonology, University Hospital of Strasbourg, Strasbourg, France; ${ }^{4}$ Department of Public Health, University Hospital of Strasbourg, Strasbourg, France; ${ }^{5}$ UMR-S1113, FMTS, Strasbourg University, Strasbourg, France; ${ }^{6}$ Department of Thoracic Surgery, University Hospital of Strasbourg, Strasbourg, France

Contributions: (I) Conception and design: E Quoix, A Charloux; (II) Administrative support: E Quoix, PE Falcoz; (III) Provision of study materials or patients: C Matau, PE Falcoz; (IV) Collection and assembly of data: C Matau, O Rouyer; (V) Data analysis and interpretation: J Jégu, E Quoix, A Charloux; (VI) Manuscript writing: All authors; (VII) Final approval of manuscript: All authors.

Correspondence to: Anne Charloux. Service de Physiologie et d'Explorations Fonctionnelles, Nouvel Hôpital Civil, Hôpitaux Universitaires de Strasbourg, BP 426, 1 Place de l’Hôpital, 67091 Strasbourg Cedex, France. Email: Anne.Charloux@chru-strasbourg.fr.

Background: Postoperative stroke is a rare complication after lung cancer surgery but has a high mortality rate. No strategy has been recommended to detect carotid artery disease preoperatively in lung cancer patients. The main objective of this study was to evaluate whether a routine carotid duplex ultrasound (DUS) altered the preoperative management of these patients.

Methods: We performed a single-centre, retrospective study of all patients referred for lung cancer resection over a two-year period and reviewed the available carotid DUS results. We quantified the number of carotid artery disease diagnosis, the severity of the disease according to DUS results, and the number of treatments initiated preoperatively. We examined relationships between cardiovascular history and preoperative carotid artery disease diagnosis.

Results: Among the 398 consecutive lung surgery patients, 6\% had a preoperative history of stroke or transient ischemic attack, and one developed a postoperative stroke, of cardioembolic origin. Three hundred and seven patients (77\%) had preoperative carotid DUS. Carotid DUS results elicited anti-platelet therapy initiation or endarterectomy before lung resection in 7 out of these 307 patients (2.3\%). One hundred and seventy-one carotid DUS were retrospectively reviewed by an expert, who diagnosed carotid stenosis $>50 \%$ and occlusion in $2.3 \%$ and $1.2 \%$ of patients, respectively. Abnormal carotid DUS was associated with history of lower extremity artery disease $(\mathrm{P}<0.001)$, diabetes mellitus $(\mathrm{P}<0.05)$ and dyslipidemia $(\mathrm{P}<0.05)$.

Conclusions: This retrospective observational study showed that routine preoperative carotid DUS led to few carotid stenosis detection and few perioperative management alterations. Carotid artery disease diagnosis was associated with cardiovascular history and risk factors. Future studies should examine how to select patients who will benefit from a preoperative carotid DUS.

Keywords: Lung cancer; cerebrovascular disease; carotid artery disease; stroke; preoperative assessment

Submitted Mar 02, 2020. Accepted for publication Sep 18, 2020.

doi: $10.21037 /$ jtd-20-1117

View this article at: http://dx.doi.org/10.21037/jtd-20-1117 


\section{Introduction}

Cardiovascular diseases may limit lung cancer therapeutic options as they are associated with increased mortality and morbidity related to treatments $(1,2)$. In multivariate analyses, cerebrovascular and coronary diseases have emerged as independent predictors of postoperative mortality $(3,4)$. Indeed, if postoperative stroke is a rare complication, occurring in $0.5-0.6 \%$ of patients undergoing lung resection $(5,6)$, the associated mortality is high, ranging from $18 \%$ to $26 \%$ (7). Expectedly, cerebrovascular disease has been selected to be one of the four items of the Thoracic Revised Cardiac Index, a cardiovascular risk assessment tool used to select patients before lung resection (8). However, no diagnostic strategy to detect cerebrovascular disease preoperatively is recommended in published guidelines for lung cancer treatment $(9,10)$.

Guidelines on diagnosis and treatment of peripheral arterial diseases and cardiovascular before non-cardiac surgery have been recently updated (11-13). It has been recommended that patients with symptoms suggestive of transient ischemic attack (TIA) or stroke in the preceding 6 months should undergo preoperative neurological consultation as well as neurovascular and brain imaging (13). The level of evidence of this recommendation is however low. Lung cancer surgery is considered as a high-risk surgery. In addition, the prevalence of asymptomatic carotid artery disease is high in ageing patients who represent an increasing proportion of patients operated for lung cancer (14). Similarly, asymptomatic carotid artery disease is frequent in patients with lower extremity artery disease (LEAD) (15), who are at high risk for developing lung cancer (16). Whether preoperative carotid imaging could be useful before lung resection, especially in some patients' subgroups, deserves to be examined. Regarding preoperative treatment of carotid artery disease, it has been recommended that carotid revascularization should be performed first, and non-cardiac surgery postponed in patients with symptoms suggestive of TIA or stroke in the preceding 6 months (17). However, the question as to whether patients with severe asymptomatic carotid occlusive disease may benefit from preoperative carotid revascularization is unresolved (13).

In the present study, we reviewed all patients who had undergone a resection for lung cancer in our institution over a period during which a preoperative carotid duplex ultrasound (DUS) was systematically offered. The main objectives of this study were (I) to evaluate the proportion of patients whose preoperative management has been modified by carotid DUS results. (II) To evaluate the proportion of patients with carotid artery disease before lung cancer resection according to DUS. (III) To examine relationships between cardiovascular history and preoperative carotid artery disease diagnosis and treatment. We present the following article in accordance with the STROBE reporting checklist (available at http:// dx.doi.org/10.21037/jtd-20-1117).

\section{Methods}

\section{Patients}

We performed a retrospective analysis of the medical records of the patients who were referred for a lung cancer resection to the thoracic surgery department, University Hospital, Strasbourg, France, between January 2009 and December 2010. Data collected included age, sex, weight and height, and risk factors for carotid artery disease: diabetes mellitus, dyslipidemia, arterial hypertension, and smoking (18). History of vascular disease (stroke, TIA, LEAD, ischemic heart disease, and anticoagulant/ antiplatelet therapy) was recorded as a marker of global cardiovascular risk (11). History of atrial fibrillation was also collected, as potential source of cardioembolic TIA and stroke (11). Lung cancer histology, surgical procedure, as well as in-hospital pulmonary and cardiovascular complications after lung resection were recorded. The study was conducted in accordance with the Declaration of Helsinki (as revised in 2013) and the Harmonized Tripartite Guideline for Good Clinical Practice from the International Conference on Harmonization. Since data were retrieved from hospital medical record system, an informed consent form was not required. The patient's personal data were secured. The study was approved by the institutional ethics board : Comité d'éthique des Facultés de Médecine, d'Odontologie, de Pharmacie, des Ecoles d'Infirmières, de Kinésithérapie, de Maïeutique et des Hôpitaux Universitaires de Strasbourg (number 2015-73).

\section{Carotid DUS review}

The extensive medical report and/or imaging of carotid DUS performed during the preoperative assessment period were collected. Consequences of the carotid DUS results on the perioperative management (prescription or modification of anti-platelet treatment or other medical treatment, carotid revascularization, delay of surgery) were 


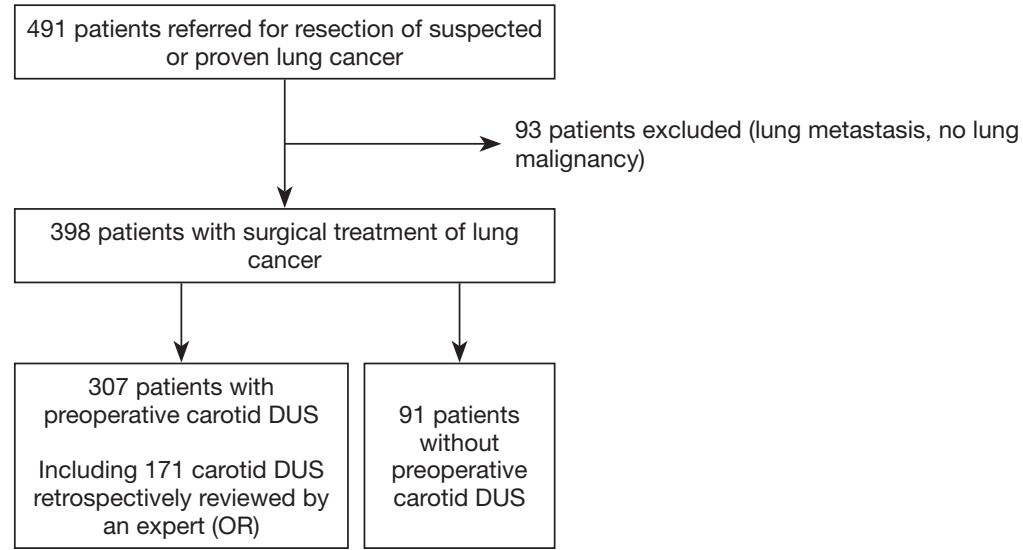

Figure 1 Patients' selection. Carotid DUS, carotid duplex ultrasound. DUS, duplex ultrasound.

recorded. In addition, the available report and imaging of the carotid DUS, which were carried out by several experienced operators in private offices or hospitals, were reviewed by a single expert (OR). We adopted the following classification, based on Grant et al. recommendations (19): absence of parietal or endoluminal abnormalities: normal; non-stenosing atheromatous lesion; stenosis $\leq 50 \%$ (without hemodynamic effect); stenosis $>50 \%$; occlusion. Patients were treated according the results of carotid DUS and following current guidelines (17).

\section{Statistics}

Firstly, a descriptive analysis of the dataset was performed with the study of patients' characteristics, postoperative complications, preoperative carotid DUS and patients' management. Frequency tables were constructed for qualitative variables. Quantitative variables were described using mean with standard deviation or median with interquartile range depending on variable distribution. Then, we studied relationships between medical history and initiation of anti-platelet therapy or carotid surgery before lung surgery. Relationships between qualitative variables (medical history, carotid DUS results) were analysed using chi-square test or exact Fischer test. $\mathrm{P}$ values are derived from two-tailed tests. All analyses were performed using STATA 12.1.

\section{Results}

\section{Patients' characteristics}

Between January 2009 and December 2010, 491 patients have been referred to the thoracic surgery department of the university hospital of Strasbourg for resection of suspected or proven primary lung cancer. Ninety-three patients with lung metastasis or benign tumour have been excluded (Figure 1). Among the 398 patients who were included, 80\% were males, $90 \%$ were current or ex-smokers, and mean age was $63.5 \mathrm{yr}$ (Table 1). The most frequent cardiovascular diseases or risk factors identified in patients' history were arterial hypertension (41\%), dyslipidemia (42\%), and body mass index (BMI) $>25$ (48\%). Six percent of patients had history of TIA or stroke. Fifty-eight percent of patients had at least two cardiovascular diseases or risk factors (smoking excluded). Anticoagulant or anti-platelet therapy was prescribed prior to lung cancer diagnosis in $7 \%$ and $27 \%$ of patients, respectively.

Lung cancer histology was adenocarcinoma in $49 \%$, squamous cell carcinoma in $37 \%$ of patients, and large cell, other or not otherwise specified in $14 \%$ (Table 2). Lobectomy/bilobectomy and pneumonectomy were the most frequent surgical procedures, being performed in $76.5 \%$ and $16.8 \%$ of the 386 operated patients, respectively.

\section{Postoperative complications}

Eleven percent of patients had in-hospital cardiovascular complications, mostly paroxysmal supraventricular tachycardia. Only one patient had stroke: a 78 yr-old male who, despite peri-operatively treated paroxysmal atrial fibrillation, was diagnosed with cardioembolic stroke 14 days after surgery. Preoperative carotid DUS had shown non-stenosing atheromatous lesion. 


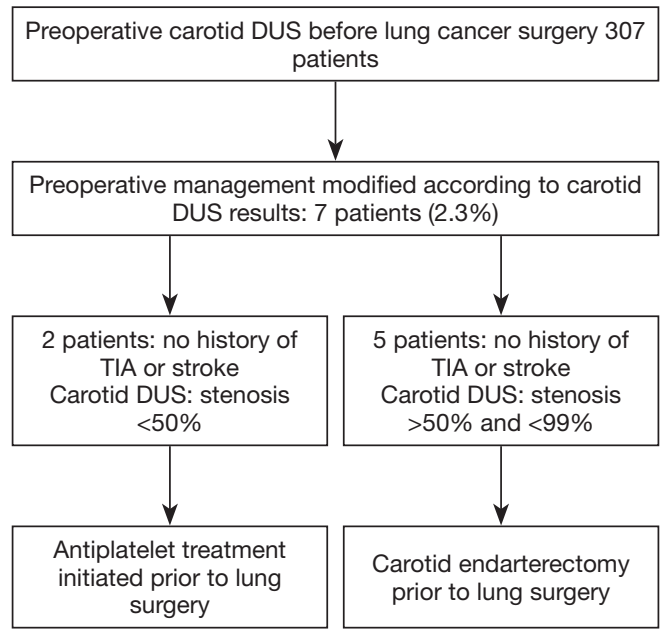

Figure 2 Consequences of carotid imaging results on perioperative lung cancer patients' management. Carotid DUS, carotid duplex ultrasound.

\section{Preoperative carotid ultrasonography and patients' management}

Among the 398 included patients, 307 (77.1\%) patients had preoperative carotid DUS. The male/female ratio was 4.79 in the group with carotid DUS, and 2.64 in the group without carotid DUS $(\mathrm{P}<0.05)$. Besides sex distribution, there was no significant difference between the two groups in terms of age, cardiovascular history, and smoking history. However, all patients with history of stroke or TIA had carotid DUS. According to the results of carotid DUS, carotid disease treatment was initiated before lung resection in seven patients $(2.3 \%)$ : two had anti-platelet treatment, and five had carotid endarterectomy (Figure 2). None of these patients had symptomatic carotid disease or history of TIA or stroke. None of these patients had postoperative cerebrovascular complication.

Among the 307 carotid DUS performed, 171 were retrieved for retrospective reappraisal. The age, sex and medical history of these 171 patients did not differ from those of patients whose US could not be reviewed. The results of this review are presented in Table 3. Non-stenosing atheromatous lesion was the most frequent diagnosis $(73.1 \%$ of patients). Stenosis $>50 \%$ and occlusion were detected in $4(2.3 \%)$ and $2(1.2 \%)$ patients, respectively.

\section{Medical bistory and patients' management}

Relationships between medical history and initiation of anti-platelet therapy or carotid surgery before lung surgery (307 patients with carotid DUS)

The seven patients in whom treatment for carotid artery disease was initiated after carotid ultrasonography had LEAD $(\mathrm{P}<0.001)$. These seven patients represented $11.7 \%$ of patients with LEAD. No statistical association was found between initiation of anti-platelet therapy or carotid surgery and ischemic heart disease, atrial fibrillation, arterial hypertension, stroke, TIA, diabetes, dyslipidemia or body mass index.

\section{Relationships between medical history and carotid} DUS results (171 reviewed carotid ultrasonography) Results of carotid DUS differed according to history of LEAD $(\mathrm{P}<0.001)$, diabetes $(\mathrm{P}=0.044)$, or dyslipidemia $(\mathrm{P}=0.047)$. Stenosis $\leq 50 \%,>50 \%$ or occlusion were detected in $38.7 \%$ of patients with LEAD but only in $7.9 \%$ without, and in $28.0 \%$ of patients with diabetes $v s .10 .3 \%$ without diabetes. These abnormalities (stenosis $\leq 50 \%$ or $>50 \%$ and occlusion) were found in $64 \%$ of patients with dyslipidemia but in $33 \%$ of patients without dyslipidemia. Three patients out of four with carotid stenosis $>50 \%$ and the two with 
Table 1 Characteristics of the 398 patients with primary lung cancer

\begin{tabular}{|c|c|}
\hline Characteristics & Outcome \\
\hline Sex & $\begin{array}{c}\text { Males: } 320(80 \%) / \text { females: } 78 \\
(20 \%)\end{array}$ \\
\hline Age & 63.5 yr (9.8) \\
\hline \multicolumn{2}{|l|}{ Medical history } \\
\hline History of smoking & 360 (90\%); pack/year: 44.4 (19.2) \\
\hline Active smoker / Ex-smoker & $228(63 \%) / 132(37 \%)$ \\
\hline Ischemic heart disease & $67(17 \%)$ \\
\hline Atrial fibrillation & $29(7 \%)$ \\
\hline Diabetes & $56(14 \%)$ \\
\hline Arterial hypertension & $163(41 \%)$ \\
\hline $\begin{array}{l}\text { Lower extremity artery } \\
\text { disease }\end{array}$ & $61(15 \%)$ \\
\hline Stroke & $13(3 \%)$ \\
\hline Transient ischemic attack & $11(3 \%)$ \\
\hline Dyslipidemia & $165(42 \%)$ \\
\hline \multicolumn{2}{|l|}{ Body mass index } \\
\hline$<18.5$ & $13(3 \%)$ \\
\hline$\geq 18.5,<25$ & $184(46 \%)$ \\
\hline$\geq 25,<30$ & $133(34 \%)$ \\
\hline$\geq 30$ & $60(15 \%)$ \\
\hline Not specified & $8(2 \%)$ \\
\hline Anticoagulant therapy & $28(7 \%)$ \\
\hline Anti-platelet therapy & $108(27 \%)$ \\
\hline
\end{tabular}

Results are expressed as number of patients (percentage) or mean (standard deviation).

occlusion had LEAD. No statistical association was found between carotid abnormalities and ischemic heart disease, atrial fibrillation, arterial hypertension, stroke, TIA, or body mass index.

\section{Discussion}

The retrospective analysis of 398 consecutive lung surgery patients including 307 patients with preoperative carotid DUS provided the following results: (I) Only one patient developed postoperative stroke, which was cardioembolic. (II) Carotid stenosis $>50 \%$ and occlusion were detected in
Table 2 Lung cancer characteristics (398 patients)

\begin{tabular}{|c|c|}
\hline Characteristics & Outcome \\
\hline \multicolumn{2}{|l|}{ Histology } \\
\hline Adenocarcinoma & $194(49 \%)$ \\
\hline Squamous cell carcinoma & $147(37 \%)$ \\
\hline Large cell & $7(2 \%)$ \\
\hline Other & $45(11 \%)$ \\
\hline Not specified & $5(1 \%)$ \\
\hline Surgical treatment & 386 patients $(97 \%)$ \\
\hline Wedge resection & $13(3.4 \%)$ \\
\hline Segmentectomy & $11(2.8 \%)$ \\
\hline Lobectomy/bilobectomy & $296(76.5 \%)$ \\
\hline Pneumonectomy & $65(16.8 \%)$ \\
\hline Exploratory thoracotomy & $1(0.5 \%)$ \\
\hline $\begin{array}{l}\text { Neoadjuvant chemotherapy/ } \\
\text { radiotherapy }\end{array}$ & $39 / 1$ \\
\hline $\begin{array}{l}\text { Surgical treatment denied after } \\
\text { multidisciplinary discussion }\end{array}$ & 12 patients $(3 \%)$ \\
\hline Carcinologic reasons & 5 \\
\hline Respiratory reasons & 2 \\
\hline Cardiovascular reasons & 2 \\
\hline Other & 3 \\
\hline
\end{tabular}

In-hospital complications after surgery (386 patients)

$\begin{array}{lc}\text { Cardiovascular } & 43(11 \%) \\ \text { Atrial fibrillation } & 25 \\ \text { Other paroxysmal } & 1 \\ \text { supraventricular tachycardia } & \\ \text { Congestive heart failure } & 6 \\ \text { Cardiac arrest } & 2 \\ \text { Acute coronary syndrome } & 2 \\ \text { Acute myocardial infarction } & 1 \\ \text { Pulmonary embolism } & 2 \\ \text { Deep venous thrombosis } & 1 \\ \text { Acute lower limb ischemia } & 1 \\ \text { Acute mesenteric ischemia } & 1 \\ \text { Stroke } & 1^{*} \\ \text { Pulmonary } & 99(26 \%)\end{array}$

Results are expressed as number of patients (percentage). *for details, see text. 
Table 3 Review of the carotid DUS of 171 patients

\begin{tabular}{lcc}
\hline & Number of patients & Percentage of patients \\
\hline No abnormality & 23 & $13.5 \%$ \\
Non-stenosing atheromatous lesion & 125 & $73.1 \%$ \\
Stenosis $\leq 50 \%$ & 17 & $9.9 \%$ \\
Stenosis $>50 \%$ & 4 & $2.3 \%$ \\
Occlusion & 2 & $1.2 \%$ \\
\hline
\end{tabular}

DUS, duplex ultrasound.

a low proportion of patients, $2.3 \%$ and $1.2 \%$, respectively. (III) Carotid DUS results elicited anti-platelet therapy initiation or carotid endarterectomy before lung resection in 7 out of 307 (2.3\%) patients. (IV) Abnormal carotid DUS was associated with history of LEAD, diabetes or dyslipidemia.

The main finding of this study is that preoperative management has been modified by carotid DUS results in only $2.3 \%$ of operated lung cancer patients. The 307 patients with carotid DUS represent a large proportion (77\%) of all patients who had undergone a lung resection for cancer in our institution over a period during which a preoperative carotid DUS was systematically offered. This low fraction of patients whose preoperative management has been modified may be partially explained by the fact that before lung cancer detection, $27 \%$ and $7 \%$ of patients were treated with anti-platelet agent and anticoagulant, respectively, a proportion close to that reported in a previous series (20). Recent guidelines emphasized that carotid imaging is not indicated routinely before noncardiac surgery procedures (13). The result of the present study strongly supports this recommendation for lung cancer resection. According to these guidelines, only symptomatic patients, e.g., with symptoms suggestive of TIA or stroke in the preceding 6 months, should undergo preoperative neurological consultation as well as neurovascular and brain imaging (13). In clinical practice this recommendation applies to a few patients operated on for lung cancer. In our series, $3 \%$ of patients had a history of stroke, and $3 \%$ of TIA, respectively. In a recent study, $3 \%$ of 1,676 surgical lung cancer patients had a history of stroke (20). In addition, since surgical patients are highly selected, it is important to consider all lung cancer patients, regardless of their treatment : in a population-based registry including 3,864 lung cancer patients, only $2-3 \%$ of patients $<70 \mathrm{yr}$ and $5-7 \%$ of patients $>70 \mathrm{yr}$ had a history cerebrovascular accident (21).

Regarding asymptomatic patients, the benefit of carotid endarterectomy before non-cardiac surgery for patients with severe asymptomatic carotid occlusive disease is still questioned. According to recent recommendations aimed at the general population, patients with $60-99 \%$ stenosis and $>5$ yr life expectancy should be proposed carotid endarterectomy (11). Therefore, identifying these patients and evaluating the benefit of carotid endarterectomy before lung resection in this group should be considered. But again, these patients are likely few. In the present study, only $3.5 \%$ of patients had stenosis $>50 \%$. In other studies, carotid stenosis was diagnosed in $7 \%$ (stenosis $>50 \%$ ) and $8 \%$ ("critical unilateral carotid stenosis without compensatory circuit or evidence of irregular potentially embolising atheromatous plaque") of surgical lung cancer patients (20,22). Similarly, before cardiovascular surgery, 7\% of patients had $>70 \%$ stenosis (23). As a result, screening for carotid stenosis should be restricted to patients at high risk for carotid atheroma.

In the present study, abnormal carotid DUS was associated with dyslipidemia, diabetes mellitus and LEAD. Of note, intermittent claudication is associated with an increased risk of cancer, with a standardized incidence ratio of 2.82 (95\% CI: 2.69-2.95) for lung cancer. This association may be explained by smoking as a shared risk factor, but also by biologic mechanisms such as hypercoagulability (24). The strong association between LEAD and carotid artery disease is well established. In a meta-analysis of studies covering a total of 4,573 patients with LEAD, the rates of asymptomatic carotid stenosis $>50 \%$ and $>70 \%$ were $25 \%$ and $14 \%$, respectively (15). There is also a strong correlation between carotid plaques and coronary artery disease in asymptomatic patients with diabetes mellitus. In addition, these patients are at risk for major cardiovascular events (25). Other risk factors for 
carotid artery disease have been identified in the literature, several of them being frequently found in combination in lung cancer patients. In a recent and large population-based study including 23,700 subjects, age, male sex, history of vascular disease, high blood pressure, dyslipidemia, diabetes mellitus and current smoking were predictors of carotid stenosis (18). Interestingly, the authors developed a score to predict carotid stenosis. Whether this score could be included in the preoperative assessment of surgical lung cancer patients to identify those who should be proposed carotid DUS deserves to be tested.

\section{Limitations of the study}

This study has several limitations, the main one being its retrospective nature. However, the strength of this study is to report real-life data, from all consecutive patients referred to a university hospital over a 2 -year period. These data should contribute to filling a gap in the literature on the preoperative assessment of lung cancer patients.

The results we report should be interpreted in the light of our patients' characteristics. Firstly, carotid DUS was systematically offered, but was not done in $23 \%$ of patients. Sex ratio was the only difference we recorded between patients with and without carotid DUS, but an impact of this bias on our results cannot be totally excluded. Secondly, our series is characterized by a high proportion of patients with LEAD (15\%) whereas LEAD is reported in grossly $3-4.5 \%$ of patients undergoing lung cancer resection in the published series $(6,20,22)$. This may be explained by a high rate of smokers $(90 \%)$ in our series, and especially of heavy smokers as reflected by a mean pack/year of 44. Indeed, smoking is a particularly strong risk factor for LEAD. Current smoking versus non-smoking has been shown to at least double, and in some studies multiply by four the odds of LEAD (26).

The small number of postoperative cerebrovascular events (one stroke, $0.25 \%$ of patients) precludes the assessment of risk factors for stroke. However, this incidence is close to those previously published for noncardiac surgery $(<0.1-0.9)(7,27,28)$. Despite the small number of patients whose preoperative management has been modified by carotid DUS results, we found significant statistical associations between this condition and LEAD, dyslipidemia or diabetes mellitus. This result should prompt validation of indexes based on medical history to select lung cancer patients who would benefit from preoperative carotid DUS. The lack of relationships with other known risk factors for carotid artery disease, such as arterial hypertension, is likely due to a lack of statistical power.

Eventually, the classification of carotid artery lesions we adopted was based on Grant et al. recommendations (19). However, we did not differentiate moderate (50-69\%) and severe (70-99\%) stenosis, as previously recommended $(29,30)$. Indeed, the retrospective analysis of the images did not allow an accurate differentiation in all cases. Nevertheless, combining these two degrees of severity in our study could be justified by the fact that $>50 \%$ stenosis is an important threshold: $>50 \%$ stenosis may have significant hemodynamic consequences during the perioperative period, and carotid endarterectomy should be discussed in both $50-69 \%$ and $70-99 \%$ stenosis in symptomatic patients (11). On the other hand, a $>60 \%$ stenosis threshold has been selected for asymptomatic patients (11), which does not fit with the carotid DUS classification (29,30).

In conclusion, this retrospective, single-center, observational study showed that routine preoperative carotid DUS led to few carotid stenosis detections and few perioperative management modifications. These results question the usefulness of routine carotid DUS before lung cancer surgery. Future well-designed controlled studies should examine how to select patients at risk of carotid stenosis who may benefit from a preoperative carotid DUS.

\section{Acknowledgments}

We are indebted to Samy Talha and Bernard Geny, who provided the greatest assistance in the carotid DUS testing of our patients.

Funding: None.

\section{Footnote}

Reporting Checklist: The authors have completed the STROBE reporting checklist. Available at http://dx.doi. org/10.21037/jtd-20-1117

Data Sharing Statement: Available at http://dx. doi. org/10. 21037/jtd-20-1117

Conflicts of Interest: All authors have completed the ICMJE uniform disclosure form (available at http://dx. doi. org/10. 21037/jtd-20-1117). The authors have no conflicts of interest to declare. 
Ethical Statement: The authors are accountable for all aspects of the work in ensuring that questions related to the accuracy or integrity of any part of the work are appropriately investigated and resolved. The study was conducted in accordance with the Declaration of Helsinki (as revised in 2013) and the Harmonized Tripartite Guideline for Good Clinical Practice from the International Conference on Harmonization. Since data were retrieved from hospital medical record system, an informed consent form was not required. The patient's personal data were secured. The study was approved by the institutional ethics board: Comité d'éthique des Facultés de Médecine, d'Odontologie, de Pharmacie, des Ecoles d'Infirmières, de Kinésithérapie, de Maïeutique et des Hôpitaux Universitaires de Strasbourg (number 2015-73).

Open Access Statement: This is an Open Access article distributed in accordance with the Creative Commons Attribution-NonCommercial-NoDerivs 4.0 International License (CC BY-NC-ND 4.0), which permits the noncommercial replication and distribution of the article with the strict proviso that no changes or edits are made and the original work is properly cited (including links to both the formal publication through the relevant DOI and the license). See: https://creativecommons.org/licenses/by-nc-nd/4.0/.

\section{References}

1. Law TD, Boffa DJ, Detterbeck FC, et al. Lethality of cardiovascular events highlights the variable impact of complication type between thoracoscopic and open pulmonary lobectomies. Ann Thorac Surg 2014;97:993-9.

2. Leduc C, Antoni D, Charloux A, et al. Comorbidities in the management of patients with lung cancer. Eur Respir J 2017;49:1601721.

3. Brunelli A, Salati M, Rocco G, et al. European risk models for morbidity (EuroLung1) and mortality (EuroLung2) to predict outcome following anatomic lung resections: an analysis from the European Society of Thoracic Surgeons database. Eur J Cardiothorac Surg 2017;51:490-7.

4. Fernandez FG, Kosinski AS, Burfeind W, et al. The Society of Thoracic Surgeons Lung Cancer Resection Risk Model: Higher Quality Data and Superior Outcomes. Ann Thorac Surg 2016;102:370-7.

5. Lewis DJ, Al-Ghazawi SS, Al-Robaidi KA, et al. Perioperative stroke associated in-hospital morbidity and in-hospital mortality in common non-vascular nonneurological surgery. J Clin Neurosci 2019;67:32-9.
6. Bateman BT, Schumacher HC, Wang S, et al. Perioperative acute ischemic stroke in noncardiac and nonvascular surgery: incidence, risk factors, and outcomes. Anesthesiology 2009;110:231-8.

7. Selim M. Perioperative stroke. N Engl J Med 2007;356:706-13.

8. Thomas DC, Blasberg JD, Arnold BN, et al. Validating the Thoracic Revised Cardiac Risk Index Following Lung Resection. Ann Thorac Surg 2017;104:389-94.

9. Brunelli A, Charloux A, Bolliger CT, et al. on behalf of the European Respiratory Society and European Society of Thoracic Surgeons Joint Task Force on Fitness for Radical Therapy. ERS-ESTS clinical guidelines on fitness for radical therapy in lung cancer patients (surgery and radiochemotherapy). Eur Respir J 2009;34:17-41.

10. Brunelli A, Kim AW, Berger KI, et al. Physiologic evaluation of the patient with lung cancer being considered for resectional surgery: Diagnosis and management of lung cancer, 3rd ed: American College of Chest Physicians evidence-based clinical practice guidelines. Chest 2013;143:e166S-90S.

11. Aboyans V, Ricco JB, Bartelink MEL, et al. 2017 ESC Guidelines on the Diagnosis and Treatment of Peripheral Arterial Diseases, in collaboration with the European Society for Vascular Surgery (ESVS): Document covering atherosclerotic disease of extracranial carotid and vertebral, mesenteric, renal, upper and lower extremity arteriesEndorsed by: the European Stroke Organization (ESO)The Task Force for the Diagnosis and Treatment of Peripheral Arterial Diseases of the European Society of Cardiology (ESC) and of the European Society for Vascular Surgery (ESVS). Eur Heart J 2018;39:763-816.

12. Fleisher LA, Fleischmann KE, Auerbach AD, et al. 2014 ACC/AHA guideline on perioperative cardiovascular evaluation and management of patients undergoing noncardiac surgery: executive summary: a report of the American College of Cardiology/American Heart Association Task Force on Practice Guidelines. Circulation 2014;130:2215-45.

13. Kristensen SD, Knuuti J, Saraste A, et al. 2014 ESC/ ESA Guidelines on non-cardiac surgery: cardiovascular assessment and management: The Joint Task Force on non-cardiac surgery: cardiovascular assessment and management of the European Society of Cardiology (ESC) and the European Society of Anaesthesiology (ESA). Eur Heart J 2014;35:2383-431.

14. Venuta F, Diso D, Onorati I, et al. Lung cancer in elderly patients. J Thorac Dis 2016;8:S908-14. 
15. Ahmed B, Al-Khaffaf H. Prevalence of significant asymptomatic carotid artery disease in patients with peripheral vascular disease: a meta-analysis. Eur J Vasc Endovasc Surg 2009;37:262-71.

16. Paraskevas KI, Mikhailidis DP, Veith FJ. Patients with peripheral arterial disease, abdominal aortic aneurysms and carotid artery stenosis are at increased risk for developing lung and other cancers. Int Angiol 2012;31:404-5.

17. European Stroke O, Tendera M, Aboyans V, et al. ESC Guidelines on the diagnosis and treatment of peripheral artery diseases: Document covering atherosclerotic disease of extracranial carotid and vertebral, mesenteric, renal, upper and lower extremity arteries: the Task Force on the Diagnosis and Treatment of Peripheral Artery Diseases of the European Society of Cardiology (ESC). Eur Heart J 2011;32:2851-906.

18. de Weerd M, Greving JP, Hedblad B, et al. Prediction of asymptomatic carotid artery stenosis in the general population: identification of high-risk groups. Stroke 2014;45:2366-71.

19. Grant EG, Benson CB, Moneta GL, et al. Carotid artery stenosis: gray-scale and Doppler US diagnosis--Society of Radiologists in Ultrasound Consensus Conference. Radiology 2003;229:340-6.

20. Shoji F, Takeo S, Yamazaki K, et al. Impact of Preoperative Ultrasonography Screening for Carotid Artery Stenosis in Lung Cancer Patients. Ann Thorac Surg 2018;106:1047-54.

21. Janssen-Heijnen ML, Schipper RM, Razenberg PP, et al. Prevalence of co-morbidity in lung cancer patients and its relationship with treatment: a population-based study. Lung Cancer 1998;21:105-13.

22. Ambrogi V, Pompeo E, Elia S, et al. The impact of

Cite this article as: Charloux A, Matau C, Jégu J, Rouyer O, Falcoz PE, Quoix E. Should we screen patients for carotid artery disease before lung cancer resection? J Thorac Dis 2020;12(11):6743-6751. doi: 10.21037/jtd-20-1117 cardiovascular comorbidity on the outcome of surgery for stage I and II non-small-cell lung cancer. Eur J Cardiothorac Surg 2003;23:811-7.

23. Ansari S, Tan JY, Larcos GS, et al. Low prevalence of significant carotid artery disease on ultrasound in patients proceeding to coronary artery bypass surgery. Intern Med J 2011;41:658-61.

24. Onega T, Baron JA, Johnsen SP, et al. Cancer risk and subsequent survival after hospitalization for intermittent claudication. Cancer Epidemiol Biomarkers Prev 2015;24:744-8.

25. Jeevarethinam A, Venuraju S, Dumo A, et al. Usefulness of Carotid Plaques as Predictors of Obstructive Coronary Artery Disease and Cardiovascular Events in Asymptomatic Individuals With Diabetes Mellitus. Am J Cardiol 2018;121:910-6.

26. Criqui MH, Aboyans V. Epidemiology of peripheral artery disease. Circ Res 2015;116:1509-26.

27. Kikura M, Bateman BT, Tanaka KA. Perioperative ischemic stroke in non-cardiovascular surgery patients. J Anesth 2010;24:733-8.

28. Mashour GA, Shanks AM, Kheterpal S. Perioperative stroke and associated mortality after noncardiac, nonneurologic surgery. Anesthesiology 2011;114:1289-96.

29. Randomised trial of endarterectomy for recently symptomatic carotid stenosis: final results of the MRC European Carotid Surgery Trial (ECST). Lancet 1998;351:1379-87.

30. Rothwell PM, Howard SC, Spence JD, et al. Relationship between blood pressure and stroke risk in patients with symptomatic carotid occlusive disease. Stroke 2003;34:2583-90. 